\title{
Optimality vs. Intent: Limitations of Dennett's Artifact Hermeneutics
}

\author{
Krist Vaesen \& Melissa van Amerongen \\ Eindhoven University of Technology \\ Section Philosophy and Ethics of Technology \\ Den Dolech 2, 5612 AZ Eindhoven \\ The Netherlands \\ k.vaesen@tue.nl
}

accepted for publication in Philosophical Psychology

\begin{abstract}
Dennett has argued that when people interpret artifacts and other designed objects (such as biological items) they rely on optimality considerations, rather than on designer's intentions. On his view, we infer an item's function by finding out what it is best at; and such functional attribution is more reliable than when we depend on the intention it was developed with. This paper examines research in cognitive psychology and archaeology, and argues that Dennett's account is implausible. We conclude that, quite in contrast to Dennett, intentional considerations play a crucial role in artifact hermeneutics, and even stronger, are necessary for the sake of simplicity and precision. Finally, we question Dennett's contention that the interpretation of artifacts is the same project as the interpretation of any other designed entity.
\end{abstract}




\section{Introduction}

Human beings are proficient in operating pens, pocket calculators, paper, paperclips, television sets, cars, microwave ovens, the bottles they drink beer out, automatic adjustable waterbeds and so forth. They understand that clothes are to keep them warm, that soap is useful to wash their hands, they know how to turn lights on and off and successfully figure out their word processor's automatic numbering habits so as to know how to change them. Failing to understand the purposiveness of man-made objects comes close to failing to live in an environment that is pervasively artifactual.

Tool use indeed is routinely cited as a paradigmatic behavior involved in high-level cognition; together with language it is by many even considered as typically human, as a quality that distinguishes us from other animals (Preston, 1998). In contrast to language, however, it has curiously received little attention in the philosophical literature (Dipert, 1993). Dennett is an exception. In several writings Dennett $(1978,1989,1990,1995)$ has considered the cognitive why's and how's of what he calls artifact hermeneutics, that is, the way people discover what an artifact is for. To explain how people interpret artifacts, Dennett relies on the notion of the design stance, a stance "where one ignores the actual (possibly messy) details of the physical constitution of an object" (1978, p. 16), and determines what it is for under the assumption that it is optimal. This assumption means one assumes both that the explanandum has a capacity to fulfill the role it has been designed to-i.e. it doesn't malfunction — and that its designer didn't do anything in vain, that is, every component of the object has a raison $d$ 'être and contributes to the object's well-functioning (see for instance Dennett, 1995, p.212-213). The reasonableness of a function ascription should be set against these constraints; to determine the function of an artifact we look at what the artifact would be best able to do. If we find an artifact that would be perfectly able to, say, pit cherries (and 
nothing else), it is a cherry-pitter. Or as Dennett writes (1990, p. 184): "It counts against the hypothesis that something is a cherry-pitter, for instance, if it would have been a demonstrably inferior cherry-pitter." It is a cherry-pitter, no matter what the object's designer or its users intended it to be. In other words, function interpretation is not an interpretation of intentions: "what something is really for now is no more authoritatively fixed by the current user's 'intentions' than by any other intentions (Dennett, 1990, p.194)."

As will be explained in subsequent sections, Dennett's proposal has two readings, a descriptive and a normative one: on many occasions it aspires to describe actual artifact hermeneutical practice, but often it also presents methodological advice about how to interpret. Accordingly, the objective of this paper is twofold. Based on recent findings in cognitive psychology and on an examination of archaeological practice, we first argue that Dennett's project doesn't live up to its descriptive ambitions. In particular, we show that intentionalistic approaches often do a better job in describing how people reason about artifacts. In a second step, we explain why the (normative) recommendation to ignore intentions is ill-advised. At the end of the paper, we briefly discuss how our observations affect the broader interpretationist program Dennett endorses.

\section{Artifact Hermeneutics According To Dennett}

Dennett's suggestion displays striking similarities to an idea that was already dominant in the literary criticism of mid-twentieth century-the so-called New Criticism. In their seminal paper 'The Intentional Fallacy' Wimsatt \& Beardsley for instance argue "that the design or intention of the author is neither available nor desirable as a standard for judging the success of a work of literary art (Wimsatt \& Beardsley, 1954, p. 3)." Instead the meaning of a poem 
should be assessed in terms of optimality (ibidem, p.4): "Judging a poem is like judging a pudding or a machine. One demands that it work. It is only because an artifact works that we infer the intention of an artificer." It is obvious what kind of literary criticism Wimsatt cum suis are attacking: traditional theories that take as primary focus the meaning intended by the author. Regarding the interpretation of artifacts, Dennett attacks a similar audience; he opposes those who refer to designer's intent to answer the question what an object is for. As such he fights a seemingly common-sensical intuition, one that has inspired the accounts of Dipert (1993), Vermaas \& Houkes (2003), and McLaughlin, who writes: "An entity is an artifact and has a particular artifactual function if it is assembled, reassembled, or virtually reassembled with that particular purpose in mind (McLaughlin, 2001, p. 55)."

Dennett has several reasons to adopt an anti-intentionalistic strategy. First, it fits well with his insistence on the indeterminacy of intentional interpretations, the latter being explanations of intentional behavior based on belief-desire attributions and a rationality assumption ${ }^{1}$. Inscrutability of interpretation regarding human behavior means that there are no deeper facts that can settle the matter unequivocally if conflicting interpretations arise; for Dennett, the idea of precise and determinate content is wishful thinking. And to be clear, it regards any kind of human behavior, including artifact creation. Not even the designer herself may know what exactly her intentions were when creating an artifact: "The inventor is just another user, only circumstantially and defeasibly privileged in his knowledge of the functions and uses of his device (Dennett, 1990, p. 186, italics added)." So, intentions are not reliable indicators of function, for the simple reason that they are unreliable indicators, full stop.

Second, designer intentions do not fix an artifact's function, since no artifact is immune to losing its original function. Indeed, old-fashioned sad-irons may be turned into 
bookends and many European churches are nowadays used exclusively to host non-religious events. In such cases, we cannot infer from intended function to current function. Put differently, designer's intentions are simply irrelevant.

Finally, Dennett defends a notion of function devoid of intentionality, because he wants it to apply to both technical and biological items. Even stronger, he aims to establish that the interpretation of people, biological traits, texts and artifacts are entirely "the same project addressed to different objects (Dennett, 1990, p. 177)." For a severe anti-creationist like Dennett, biological functions are not intentionally designed. Hence, for his generic account to work, intentions cannot be taken as a starting point for reasoning about functions ${ }^{2}$.

These three reasons might for Dennett be sufficient to reject intentional approaches, but he nowhere offers a real positive argument in favor of his alternative, viz. a design stance relying on mere optimality. Instead, its plausibility is illustrated by a number of examples. To see the design stance at work, Dennett refers for instance to reverse engineering:

"When Raytheon wants to make an electronic widget to compete with General Electric's widget, they buy several of GE's widgets and proceed to analyze them: that 's reverse engineering. They run them, bench-mark them, X-ray them, take them apart, and subject every part of them to interpretive analysis: Why did GE make these wires so heavy? What are these extra ROM registers for? [...] Notice that the reigning assumption is that all these "why" questions have answers. Everything has a raison $d$ 'être; GE did nothing in vain.[...] If the reverse engineer can't assume that there is a good rationale for the features they observe, they can't even begin their analysis (Dennett, 1995, p.212-213)." 
Moreover, Dennett mentions archaeologists and historians interpreting the archaeological record. These have for instance discovered the Antikythera mechanism ${ }^{3}$ to be an orrery or a planetarium, and the "proof of that is that it would be a good orrery (Dennett, 1990, p.184)." One has calculated the periods of the rotation of its wheels and found out that the artifact would have made an accurate representation of what was then known about planets and their motion paths. If so, Dennett argues, the function attribution-which is almost certainly correct—came about without relying on original intent. Rather, it was established via an examination of the purposes the unknown object optimally could have served.

Both arguments are descriptive: Dennett pictures the real-life practice of engineers, archaeologists and historians, that is, the way they involve in functional reasoning. Elsewhere however, the design stance seems more like a methodological advice. When interpreting a robot, for instance, Dennett recommends us to consider it "in the context of the costs and benefits of its current environment", since in this way "we may arrive at a better interpretation of its internal states than its original designers can muster (Dennett, 1990, p. 186, italics added)." Elsewhere we read: "Curiously, then, we get better grounds for making reliable functional attributions [...] when we ignore "what people say" and read what function we can off the discernible prowesses of the objects in question, rather than off the history of design development (Dennett, 1987, p. 319)."

In the following sections we will consider both the descriptive and normative reading. For the sake of clarity, we summarize them as follows:

[D] In artifact hermeneutics, people reason in terms of optimality, rather than in terms of intentions. 
[N] In artifact hermeneutics, people should reason in terms of optimality, rather than in terms of intentions.

Before discussing $[\mathrm{D}]$ and $[\mathrm{N}]$, we need to clarify one last ambiguity in Dennett's account ${ }^{4}$. Artifact hermeneutics, as said, is about discovering the function(s) of an artifact. But what exactly does this mean—at least according to Dennett?

Given the importance Dennett attributes to optimality, we can dismiss two interpretations from the outset. According to the first, artifact hermeneutics aims to settle the question: "What does artifact $\mathrm{X}$ afford?" In other words, it is the artifact's possible function(s) we are after. But possible functions are, per definition, all those that an artifact are able to perform independent from some sort of optimality standard; we only require the artifact to have the capacity to realize the function(s) in question. For instance, Dennett is not interested in all the possible function ascriptions archaeologists may come up with respect to the Antikythera mechanism - after all, the object may be used for a wide variety of things, e.g. as a hammer, a paperweight, an electric conductor. Rather, the author aims to explain how archaeologists derive one (i.e. the most salient) interpretation which establishes "the" (alleged) function(s) of the device.

According to the second implausible interpretation, artifact hermeneutics addresses the question: "What does artifact $\mathrm{X}$ afford right now?" In this case, we are interested in the device's current function. But again, optimality considerations are redundant in this regard. Determining what artifact $\mathrm{X}$ is currently used for can be done without us needing to consider whether the device is used for the things it is best able to do. Seeing an archaeologist using the Antikythera mechanism as a paperweight provides me with perceptual evidence for the 
artifact's current function. I may appreciate that such usage is suboptimal, but my finding does not affect (the reasonableness of) my original interpretation.

In a more plausible reading, artifact hermeneutics concerns-for Dennett at least- the question: "What function is artifact X meant to afford?" If so, Dennett addresses, somewhat paradoxically, the issue of discovering what we might call intended function. This might strike the reader as odd, for didn't Dennett exactly want an account of function devoid of intentionality? It is important to appreciate, however, what intended function means, and what not. For Dennett, function interpretation indeed involves intentions, but these are to be explained, rather than explaining. So, in order to determine intended function we do not (or should not) take intentions as a starting point, but rather optimality. We thus start from assumptions of optimality, and based on that, we then may infer intended function ${ }^{5}$; the archaeologist looks for the purposes the Antikythera mechanism might have served for the people once producing and/or using the object. And what the Antikythera mechanism is best able to do is indicative of what it presumably was intended for-put differently, of what it was meant to afford. In sum, we should look at what the object in question affords best, and not at what people say or have said about it.

Note moreover that intended function is not always equal to original intended function; what an artifact is meant to afford may be determined by its designer(s), but also by its users. In the latter case, the intended function of say, a sad-iron being turned into a bookend, is altered, whereas its original intended function remains intact. This should not be surprising: what was once optimal may be, due to technological progress for instance, suboptimal on a later date. In other words, the original intended function of an artifact may over time become obsolete. Given Dennett's treatment of the sad-iron example, we may infer that the author discusses the meaning of artifacts irrespective of who (i.e. designer or user) it was 
that meant them to afford this or that. In other words, the author is concerned with intended function in general, not merely original intended function.

In sum, we believe that it is more plausible to assume that Dennettian artifact hermeneutics concerns intended function, rather than possible or current function. Our paper's task then is to show that to settle the question "What is artifact X meant to afford?", peoplecontra Dennett—do not (or should not) merely rely on optimality standards, but also (should) take intentional considerations aboard.

\section{Artifact Hermeneutics According To Cognitive Psychology}

If claim [D] is to count as an empirical claim, it should give us an accurate description of how real-life people commonly reason about artifacts. But in fact, it doesn't. To see why, it is instructive to have a look at recent research in cognitive psychology on how children infer what artifacts are for. Roughly, the research can be subdivided in two research traditions, an essentialist and an anti-essentialist one. And although these disagree on some points, the results of both can be used to challenge Dennett's account.

Let us start with the essentialist tradition. Many scholars working in this tradition have, directly borrowing from Dennett, labeled the human strategy to interpret man-made objects the 'design stance' (see for instance Kelemen, 1999a, 1999b; Defeyter and German, 2003; German and Johnson, 2002; Kelemen and Carey, 2006). Surprisingly, though, these authors have given the term quite a different meaning ${ }^{6}$ : for them the design stance refers to the cognitive capacity to categorize and reason about artifacts on the basis of the original intentions with which these objects were produced (and thus not in terms of Dennett's nonintentional optimality considerations). In fact, this idea is the core idea of the essentialist program: people reason about artifacts according to an 'essence', namely original intent ${ }^{7}$. This 
means that original intended function overrides such factors as appearance and context and actual use as the basis for how humans categorize artifacts.

It is around the age of five or six that the design stance-in the sense defined abovegets mature - at least according to authors such as German and Johnson (2002), Kelemen (1999b), Matan and Carey (2001), and Defeyter and German (2003). One way to test their intentional bias proceeds by confronting subjects with objects having a clear original intended function, but used in an improper way. Kelemen (1999b), for instance, presented people of different age with a picture of an artifact. The subjects were told that the object was made by a person who intended it to be a thing to stretch clothes- the person needed such tool, since his wardrobe got shrunk by his washer. Moreover, they were informed that the artificer, after a onetime use, gave the artifact to a friend, and that the friend used the thing to stretch and exercise her bad back. When asked what the object was for, subjects predominantly answered it to be for drying clothes, in other words, its function was equated with the one intended by the artificer. Hence, assuming the artifact to be optimal for both tasks, there seems to be a bias towards original intent when people categorize $\operatorname{artifacts}^{8}$ - pace Dennett. For if people would not take design intentions as a starting point, we would expect an equal distribution of fifty to fifty in the responses given.

The results of another study, conducted by Gelman and Bloom (2000), point in the same direction. These scholars showed that whether the very same crude object was described as the product of intentional design or as the outcome of an accident affected how it was interpreted. For instance, a paper hat was more frequently interpreted as a hat, if subjects were told that it was intentionally designed for that purpose, than when they were informed it was the result of an accident-c.q. the result of a car running over a newspaper. If optimality would be as essential as Dennett thinks, we again would expect the object, having the same 
"optimality" in both scenarios, would be interpreted as often as a hat in both the intentional and accidental case; the apparent discrepancy in numbers, though, is explained by the fact that the subjects took intentional considerations aboard.

Another particularly interesting study, still essentialist in nature, was conducted by Kemler Nelson and colleagues (see Kemler Nelson et al. 2002 and 2004). The team investigated how people interpret broken objects. To see in what sense their efforts challenge Dennett, one should first recall what his optimality assumption amounts to. First of all, it means that one has to assume that the object one interprets isn't malfunctioning, and second, that all of its components have a raison d'être. It is the first condition which interests us here; non-malfunction must be the default assumption, otherwise it is impossible to get any interpretation off the ground ${ }^{9}$. With this in mind, let us turn to Kemler Nelson and colleagues. They showed that adults (and children, from 10 years on) interpret accidentally malfunctioning objects according to original intended function. Subjects, for instance, were presented with a damaged cup (the thing could not hold liquid because an irregular piece of its side was broken off); most of the participants nevertheless still interpreted the object as a cup. Similar results were obtained for interpretations of less familiar artifacts, such as "beckets" (a ball dispenser), "luzaks" (a tool to draw circles), and other objects specially designed for the experiment. Now, even if people would typically reason in terms of optimality, like Dennett argues, the results of this study show that humans at least at a certain point give up optimality; instead of continuing to look for a function the broken thing still can perform optimally, they attend to the intentions with which it was designed. And as important, doing away with the non-malfunction condition did not prevent reasonable interpretations getting off the ground. 
Before we consider the anti-essentialist research tradition, one remark. On some occasions, as explained in sections 2, Dennett seems to defend the claim that what an artifact is for may change over time, and may for instance be determined by its users-sad-irons interpreted as bookends being a case in point (see previous section). Although there undoubtedly is a flexibility (e.g. over time) in the interpretations people make, we should be wary to overestimate its significance. Humans appear fairly conservative; cognitive psychologists, for example, have argued that children, already at the age of six or seven, start to show the signs of "functional fixedness" (see e.g. Defeyter \& German, 2003; Casler and Kelemen, 2005). They tend to become "fixed" on the original intended function of an artifact; and it is particularly difficult for them to reason otherwise. They not only "theoretically" frame an artifact in terms of original intended design, but will actively and practically use this knowledge (or bias, if you wish) when asked to solve specific problems with the artifact. For instance, a study of Defeyter \& German (2003) showed that six-seven year old children were slower than five years old in solving a problem by using an artifact in an atypical way.

There are no clear-cut answers as to why people develop such a bias. Casler and Kelemen (2005) hypothesize that thinking in terms of original intended function provides us with a helpful shortcut in our daily interaction with artifacts; it would be highly impractical if we needed to ponder over and over again on the function of all the man-made objects we encounter. As such, it is suggested that reasoning in terms of original intent may have a place in our evolved human nature-a fact, if correct $^{10}$, Dennett as a naturalist should be glad to recognize.

Scholars in the anti-essentialist tradition are more pragmatic; they believe that humans categorize artifacts not according to some essence (such as original intent), but rather depending on the task at hand. 
Some researchers for instance have discovered a phenomenon known as the shape bias. They argue that, when people are asked to judge an object's kind, physical features are sometimes given more weight than original intent (see e.g. Malt \& Johnson, 1992; Landau, Smith \& Jones, 1998; Hampton, 1995; Baldwin, 1992; Graham, Williams \& Huber, 1990; Sloman \& Malt, 2003; but see Diesendruck, Markson \& Bloom, 2003; Gelman \& Bloom, 2000). Chaigneau (2002; see also Barsalou et al.), for example, considered cases where people have privileged access to the artificer's intentions by being told. He pitted such knowledge against other aspects of the object and considered their relative importance in judgments of the appropriateness of a label. For instance, in one scenario the experimenter intended a certain object to be a mop and used it as a mop, but the object was a bundle of plastic bags attached to a four foot long stick. Most subjects did not regard the object a mop, despite the artificer's intentions and despite the fact that it was used as such. Chaigneau concludes that physical affordances and context of use may well dominate original intentions when subjects reason about artifact categories and artifact functions.

In a similar vein, Siegel \& Callanan (2007) show that when subjects are told that many people (as opposed to one individual) use an artifact in a new way, they not strictly interpret the artifact in terms of its intended purposes; put differently, their interpretations are sensitive to apparent conventions of use. As such, the researchers criticize the 'essentialist' design stance for neglecting the ways in which tools are used in social settings.

Note, however, that both Chaigneau and Siegel \& Callanan do not claim that original design intentions are simply irrelevant to function ascription. On the contrary, the authors recognize that it is an important feature, but add that it is not the only one. For Chaigneau, physical affordances and context of use may well dominate original intentions, depending on the case at hand. Likewise, Siegel \& Callanan recognize that conventional functions of 
artifacts are typically related to their original intended function, and that this may account for the stability in our reasoning about artifacts-in other words, for our functional fixedness. Nevertheless, the authors present convincing evidence for the fact that, given its embeddedness in a social context, an artifact's meaning may change and evolve over time and culture.

So in sum, whether one adheres to an essentialist or to a more pragmatic view, it is safe to say that, according to cognitive psychology, designer's intentions play an important role in the interpretation of artifacts - the main topic of disagreement being exactly how important. And obviously, this poses a problem for the design stance as Dennett pictures it. As an empirical theory it is in conflict with a converging body of scientific evidence; it misrepresents how people usually frame artifacts. In this way, we have provided a first argument against [D]. In particular, contra [D], we have explained that to decide what an artifact is for, people (often) reason in terms of intentions-or, to use Dennett's words, in terms of what "people say"—not (only) in terms of what it the object is best able to do.

Dennett then might perhaps claim that the design stance is not so much an empirical theory about our everyday functional reasoning, but is meant to capture a methodology used in scientific artifact hermeneutics. We believe it to be unlikely that the author really would make such move, given his frequent talk about laymen interpreting sad-irons, mainframes, vending machines, chess players, robots, (fake) antiques in an antique shop, and the like, and given the fact that Dennett generally sees the stances at work both in folk and genuine science. For the author, the difference between the latter two is more a matter of degree; for instance, both folk psychology and psychology proper rely on the intentional stance, though the latter definitely adopts it in a more "systematic" way (see for instance, Dennett, 1989, especially chapter 3). But even if we prove wrong, and the design stance really is meant to 
capture only the scientific variant of artifact hermeneutics, Dennett is still in trouble, as we are to show in subsequent section.

\section{Artifact Hermeneutics In Archaeology}

What is the proper domain to evaluate the methodological attribution of functions to artifacts? Many scientific fields use a notion of function, especially in the humanities and the social sciences. But studies of artifact function are rare. An exception is archaeologyindeed, a domain frequently considered by Dennett himself. The archaeologist tries to find out the function of an artifact, and tries to do so in a scientifically respectable way.

At first sight there indeed seems a problem for a strong intentionalistic reading of the archaeological record. What the "designer" of a prehistoric artifact intended is not known (there are no user's manuals to be found). On the contrary, the record is mainly used to (re)construe the beliefs and desires_-or the mental life—of the people that used or developed the tools in question; if they had any, since we are not even sure whether early tool-makers had intentions at all. Another factor in support of Dennett is that the archaeological literature frequently refers to optimality considerations. Take for instance Salmon's rule of thumb for the archaeologist:

"The more severe the limitation on the form of an object that the suspected function imposes, the more reliable is the ascription of that function [...] For some objects, such as grinding stones, there are very few forms that are compatible with reasonably efficient performance of the function. (Salmon, 1982, p. 59)" 
The principle is relevantly similar to Dennett's optimality principle that it would count against something being a cherry-pitter, if it would be a demonstrably inferior cherry-pitter. Although these considerations speak in favor of Dennett's account, there are a number of questions that seem only resolvable by appeal to intentionality. Let us consider an example.

Near Baghdad many so-called Babylonian batteries have been found, objects belonging to the Parthian (between 250 BC and 224 AD) or Sassanian era (224-640 AD). Each so-called battery is a $15 \mathrm{~cm}$ vessel which contains a cylinder of sheet copper, capped at the bottom, in turn covering and protecting an iron rod, which shows signs of acid corrosion (see figure 1).

[FIGURE 1 here; Figure's Caption: "A so-called Babylonian Battery"]

In 1938 Wilhelm König, director of the National Museum of Iraq, published a paper suggesting that the artifact may have been a galvanic cell, a kind of primitive battery (König, 1938; see also Dubpernell, 1978). And that would indeed be a spectacular discovery if it were true. It would imply that electrical current had been used by the ancients and was only rediscovered by Galvani and Volta, some 1,800 years later.

König's hypothesis was tested by Jansen et al. (1993). They concluded that, when fueled with a solution of benzoquinone, a substance occurring naturally in the secretions of some beetles, the object could indeed produce a certain voltage $(+/-0.87 \mathrm{~V})$; in other words, physically the artifact can fulfill the function of a battery. The question- to Dennett - then is: is this sufficient to call the design optimal, and thus to conclude the thing to be a galvanic cell?

A "yes" would be—and has been—wholeheartedly embraced by proponents of the paranormal. Some of them (see for instance Ortiz de Montellano, 1991; von Daniken, 1993) find in the "power source" thesis evidence for a technologically advanced (extraterrestrial) 
civilization in remote antiquity. Most historians, however, are fairly skeptical (see for instance Eggert, 1996), since the alleged galvanic cells are contemporary with the growth and height of the Roman Empire. The latter is a fairly well-documented era, hardly a period thus in which such a civilization would have gone unrecorded, particularly when the Parthian Empire was Rome's principal enemy in the east. Furthermore, what kind of appliances would need the energy supplied by these cells? Until now, no Parthian electronic devices have been found, so at the face of it, there was no Parthian desire- hence, no belief about how to satisfy it, hence no intention — to produce electricity whatsoever.

The hypothesis that the Babylonian vessel was used as a storage device for sacred scrolls, which were wrapped around the iron rod-as, among others, Paszthory (1989) suggests—seems more plausible — and more accepted — than the "power source" hypothesis, but not unequivocally in the light of optimality. Indeed, the vessels are good at storing parchment or papyrus, but why would they need an iron rod and a copper cylinder (and an asphalt seat at the bottom and an asphalt stopper on top)? In engineering terms, the artifact is over-designed; and thus it would be in conflict with Dennett's optimality principle which states that every artifact's component should have a raison d' être. Besides, if one thinks overdesign is unproblematic, why not just claim the artifact to be a container full stop, or a container of air? Because without the restriction of over-design, such hypothesis would be just as reasonable as the "power source" hypothesis.

More important for our purposes, to come to his conclusions, Paszthory reasons in terms of intent, not mere optimality. He explains iron and copper to have a magical meaning, playing a role in ancient alchemy. According to the Parthians, it might well have been that the use of these metals was meant to please the gods ${ }^{11}$, an attempt to protect their sacred documents against divine terror. As such, Paszthory hypothesizes about what Parthians could 
and couldn't have meant the artifact to be for-inferring from knowledge about their beliefs and desires - to adjust his interpretation accordingly. The example illustrates that, pace Dennett, a methodologically sound interpretation of an artifact may well involve an interpretation of intentions, beliefs and desires (and thus intentions), be it of the supposed creator of the artifact in question, or more generally, of the people who used it.

Successful experiments in experimental archaeology, as Eggert (1996) remarks, can only show a supposed ancient technique to be possible, but never its application. For instance, when Thor Heyerdahl crossed the Atlantic in an Egyptian boat, he only showed that it was possible, in principle, for the Egyptians to have done likewise. But to accept the claim that they indeed did, one would need archaeological evidence from America. Similarly, one should be wary of interpreting the experimental evidence about the Babylonian vessels as decisive. Even if the vessels can generate current-perhaps even optimally-this doesn't prove that they once did. In contrast, the example shows to what kinds of anomalies optimality conditions can lead, if not constrained by some kind of intentional reading; we sincerely do not believe extraterrestrial visitors once learnt the Parthians to produce energy. And if they did, they were remarkably parsimonious; being visitors with space travel capabilities, why didn't they show the Parthians less primitive ways of producing energy?

In fact, these remarks also apply to the examples Dennett himself gives. For instance, Dennett considers William Calvin's analysis of the so-called Acheulian hand axe (Calvin, 1986). The object is an artifact mainly found in Ethiopia. It is a flattish stone arising about 1.8 million years ago (see figure 2).

[FIGURE 2 here; Figure's Caption: "An Acheulian hand axe"]

For a long time it was thought that the object was a kind of hand axe, a thing used for instance for butchering. But actually, it would be a fairly poor hand axe. Along its entire 
perimeter, the stone displays a sharp edge, not by accident, but because of some form of (primitive) design. So if the stone were to be used as a hand axe, its user would cut herself. Relying on optimality considerations, then, the hypothesis that the artifact is a hand axe is counted against by the fact that it would have been a demonstrably inferior hand axe. On similar grounds, Calvin rejected the suggestion that the object was a skinning device. He referred to a set of performance studies, showing that for scraping animal hides, blunt stones do a better job. Finally, he discovered that the object could be thrown as a discus, while it would neatly rotate in a vertical plane. Moreover, he found out the reason for the object's sharp perimeter. Hit by a blunt stone, Calvin argues, an animal doesn't topple; it reacts by extending its overlying leg, remaining in balance. But if it is hit by the Acheulian artifact, it collapses; the incision pain causes a flexion reflex, both hind legs are withdrawn, and the animal will sit down or fall to the overlying side.

Indeed, the example seems to speak in favor of Dennett's optimality account. But Calvin's suggestion only works if we make a set of additional assumptions. For one thing, we have to hypothesize about what the Acheulian hominids needed and wanted, and what they could know and do. We have to treat them as intentional systems, and rationalize their killer discus producing and using behavior. For instance, suppose we know the Acheulians were strictly vegetarian, implying they didn't need—or intend—-to kill mammals at all. In that case, the production of hunting gear would be irrational, making our "killer discus" hypothesis less convincing; the hypothesis that the artifact is a killer discus is counted against by the fact that it would have been a demonstrably useless artifact. Calvin's experiments have indeed shown one of the object's possible capacities, but the reasonableness of his suggestion is dependent on a set of implicit assumptions about the Acheulian intentional life. 
All in all, we do not deny that optimality considerations are of enormous importance for generating hypotheses and theories. But the plausibility of such hypotheses, and their experimental validation, goes beyond the simple rule of thumb that we should in principle expect artifacts to fulfill or to have fulfilled an optimal function. Even if the intentions of early artifact designers and users are indeterminate — as said, one of the reasons for Dennett to discard intentionalistic approaches-this does not mean it is unproductive to hypothesize about them; indeterminacy is simply part of the hermeneutical game.

Consequently, we think [D] is inaccurate and far too radical to explain scientifically respectable artifact hermeneutics. In particular, this section has shown that archaeologists reason to function, both from optimality and intent. A next step in our argument, now, is to prove the normative claim $[\mathrm{N}]$ to be in bad shape.

\section{A Normative Design Stance: Cui Bonum?}

To ground the recommendation $[\mathrm{N}]$, we would need an argument that shows that people would be better off, that they, say, would have been better adapted to their artifactual environment if they paid no heed to designer's intentions. Some simple examples suffice to falsify this claim.

First, suppose one buys a DVD-player. The first thing one arguably does at home is read the user's manual and interpret the text written by the manufacturer. One takes her as an authority with respect to the intended functions of the player and its buttons. Even in the unlikely case that the DVD-player did not come with a manual, one can easily deduce some of its functionality relying on the labels on the buttons. The play-button, for instance, usually is colored green or tagged with a triangle pointing to the right; or the manufacturer simply might have written "Play" on it. As one treats the designer as a rational, intentional system, 
one can assume she has tried rationally to convey a message; she did not want to deceive the player's prospective users. On the contrary, hoping they can operate the object without much ado, she intends them to recognize what the buttons are really meant for.

It is particularly hard to find a reason why users would or should discard or distrust such information. It gets even more puzzling if one recognizes that Dennett himself thinks that communication can only proceed assuming the other to be rational, and even stronger, to be a truthful communicator:

The faculty of communication would not gain ground in evolution unless it was by and large the faculty of transmitting true beliefs, which means only: the faculty of altering other members of the species in the direction of more optimal design. (Dennett, 1978, p. 18)

In other words, it pays off to assume, by default, that the utterer (i.e. the designer) transmits reliable information to the artifact's prospective users.

Perhaps Dennett thinks that, in contrast to "regular communication" (as described in the quote above), "artifact communication" does not rely on a rationality assumption. But why would he argue for this? If deception (and not rationality) is the default assumption, it is hard to explain why human beings are so efficient in interpreting and using artifacts. Relying on designers' cues to original intent is typically a straightforward and fruitful strategy. After all, if it were not, designers presumably wouldn't put so much effort in developing comprehensible manuals, labels and product lay-outs. In fact, to make an artifact selfexplaining, designers reduce the number of possible interpretations. It implies they try to be as suggestive as possible with respect to the purpose the artifact (or its components) is 
intended to serve. As a result, the cognitive demands on the interpreter of the artifact will be smaller, that is, on the condition she does not share Dennett's suspicion of (clues to) original intent.

A second consideration is malfunction. What if one inserts a DVD in the player, pushes the "Play"-button, and notices that the machine does not respond in any way? There are two things that might have gone wrong. First, the button might be malfunctioning. Second, the user's interpretation might be wrong, either because the designer successfully has fooled him—she has written "Play" but actually meant something else—or because his optimality assumption tells him so: the hypothesis that the button is a "Play"-button is counted against by the fact that it would be an inferior "Play"-button.

If the user has plenty of time, he can scrutinize the possibility of his interpretation being wrong; he investigates the button until he ends up with a stable interpretation. On the other hand, if he is more pragmatic, he presumably takes his interpretation to be right, returns the product to the vendor, and most likely will receive a new specimen.

Apparently then the easiest way to discern malfunction from incorrect function ascription is to rely on an interpretation of designer's intentions, which means again that we can get better grounds for our function attributions when we disregard optimality and the object's physical constitution-pace Dennett, pace [N]. So again it would be unwise to prefer an impractical and possibly cognitively expensive Dennettian procedure over a cheap nonDennettian trick. Like the phenomenon of functional fixedness (discussed in section 3) offers a helpful shortcut in everyday functional reasoning, we should, our cognitive capacities being limited, welcome shortcuts designers intentionally provide us with. Reasoning that is based on allegedly unreliable information (such as intentional data), can nonetheless result in the efficient achievement of practical goals (such as quickly getting a malfunctioning DVD- 
player replaced); and it is such success that should be the criterion to evaluate an instance of functional reasoning.

Besides, recall that, as explained in sections 1 and 2, Dennett reserves the design stance for non-malfunctioning artifacts; for him, optimality must be the default assumption, otherwise it is impossible to get any interpretation off the ground. But as the example illustrates, this contention seems only valid if one disregards interpretive clues with respect to original intent; albeit the fact that the "Play"-button malfunctioned, we did get a fairly reasonable interpretation off the ground.

Does the same argument hold for less complex artifacts, such as the objects used in the empirical studies of section 3? It is hard to tell. To answer the normative question we need a standard to compare to. As said, people presented with a clothing rack used as a back stretcher tend to interpret the object as a clothing rack; would they in some sense be better off if they were to interpret it as a back stretcher? Without specifying the notion "better"—c.q. better with respect to what?-our question remains pointless. An obvious sense of better would be something like "more conducive to the achievement of one's practical goals". In the experiment the clothing rack example is taken from, no such practical context is available though; consequently, goal achievement offers no ground for comparison. The best we can do is to repeat earlier, indeed fairly general suggestions; for instance, that functional fixedness (and thus, a preference for original intent) might be "good", since it makes our practical lives less cumbersome; or that, in a more pragmatic vein, what is best depends on the context at hand-sometimes, it rewards to dig for intent, on other occasions optimality (or use or convention) is the better strategy.

Unsatisfactory as these remarks might seem, they do point to the difficulties one is likely to encounter when making normative claims about artifact hermeneutics. At the least, 
they are indicative of the obstacles Dennett has to overcome if defending $[\mathrm{N}]$ in cases of nonscientific artifact interpretation: he needs to make explicit how he construes the "goodness" of an interpretation, and subsequently, offer a convincing story why his strategy is best, in all contexts - and if not in all contexts, in which ones. The burden of proof, fortunately, is on Dennett.

Finally, let us turn to the question whether $[\mathrm{N}]$ is reasonable as a recommendation for those involved in scientific artifact hermeneutics. We believe it is not. We have seen what an exclusive focus on optimality may lead to: Babylonian vessels being interpreted as galvanic cells. According to $[\mathrm{N}]$, then, such interpretation would be better than the "scroll conserving device" hypothesis, simply because the latter takes intentional information into account. Suppose we would find Babylonian rock paintings showing the Baghdad vessels indeed being used as storage devices; or a Babylonian text explaining the religious meaning of copper and iron. We guess there is no principled reason to ignore these findings. Reasonable interpretations may well not grant authority to only one type of consideration and make use of all available data instead, even if the latter are all liable to indeterminacy.

\section{Discussion}

The point of this paper was to evaluate one of the few proposals philosophers have made regarding the interpretation of artifacts. We have argued that, despite its undeniable hypothesis generating power, Dennett's design stance is insufficient to capture how peopleboth folk and scientific_-involve in artifact hermeneutics; next to that, we have explained that it is poor as a methodological advice.

An alternative to Dennett's view should refer in some way to intentions, but it is still unclear to what extent. Essentialist cognitive psychologists believe intent determines function 
ascription, whereas more pragmatic scholars see it as an important but not decisive factor. Also in archaeology it appears that interpretations of intentions are necessary-even though often implicit-to constrain what we, in light of mere optimality, think an artifact is for. Finally, cues to intent allow for straightforward, defeasibly appropriate function ascriptions. Now, if the efficient achievement of the artifact's functional goal is set as a criterion to assess the appropriateness of an interpretation, it is arguably best (more economic) to set aside the doubts we may have about the reliability of intentional information.

In section 2, we explained that one of the reasons for Dennett to endorse a nonintentional account is his ambition to establish a generic interpretive program, that is, a program that is not only applicable to artifacts, but to persons, organ(ism)s and texts alike. In (Dennett, 1990) the author claims that any such interpretation follows entirely the same strategy, viz. an optimality strategy. It is interesting to reassess this proposal, bearing in mind the findings of our paper.

For artifacts and texts we already explained what optimality amounts to. When it regards biological organ(ism)s, it means we should embrace adaptationism. The latter assumes optimality of design in the sense that it considers every part or trait of an organism to be there for a reason. For instance, if we find a bird that lays four eggs, we first assume that this number is somehow optimal: that two is not enough, and five is too much (Dennett, 1990, p.187-188). We then try to explain why four would have been the better strategy. Only if we cannot come up with a plausible story, we may grant that the trait is perhaps a bad adaptation, or perhaps an exaptation.

Dennett admits that adaptationism might not be true—as Gould and Lewontin (1979) have insisted - and that it is naive to think that evolution has made the best of all possible worlds. Nevertheless, "we must be interpreters if we are to make any progress at all, and 
interpretation requires the invocation of optimality (Dennett, 1990, p.187)." As such, assuming optimality (and adaptationism) in nature is simply an efficient way of generating questions and possible answers-just like in artifact hermeneutics, or so Dennett claims. But as we have seen, artifacts are-and should be-interpreted relying both on optimality and intentional considerations. Clearly, this hampers Dennett's unificationist aspirations.

Of course, it still might be possible to establish a generic interpretive program, including artifacts and biological items (and people and texts). One could for instance argue that organ(ism)s too are interpreted relying on optimality and intent. Granted, for Dennett we can treat natural selection as an intentional agent: "Mother Nature" selects traits, and has reasons to do so. She tries certain moves and evaluates them; smart moves stay in, whereas stupid moves disappear from view. But this sketch is nothing more than a more plastic (though metaphorical) representation of optimality: given a certain problem space, roughly, the better solutions win. What is needed to argue for the importance of intent in the interpretation of organ(ism)s, is a proof that intent reveals things that remain hidden under an optimality account or that it is beneficial to ignore optimality and dig for designer's-i.e. nature's-intentions instead. It is far from evident that such thing can be done without entering the waters of creationism. Fortunately, the burden of proof is on, if any, those who think our understanding of biofunctions is-or should be-linked to "Mother Nature's" intentionality.

\section{Acknowledgments}

Support for this work was provided by the Netherlands Organization for Scientific Research (NWO). We like to thank Anthonie Meijers, Wybo Houkes, Marc de Vries, Jesse Hughes and two anonymous referees for their comments on earlier drafts of this paper. 


\section{References}

Baldwin, D.A. (1992). Clarifying the role of shape in children's taxonomic assumption. Journal of Experimental Child Psychology, 54, p. 392-416.

Barsalou, L.W., Sloman, S.A. \& Chaigneau S.E. (2006). The HIPE theory of function. L. Carlson, E. van der Zee (eds.), Representing functional features for language and space: insights from perception, categorization and development. New York: Oxford University Press.

Calvin, W. (1986). The river that flows uphill. Sierra Club Books.

Casler, K. \& Kelemen, D. (2005). Young children's rapid learning about artifacts. Developmental Science, 8(6), p. 472-480.

Chaigneau, S.E. (2002). Studies in the conceptual structure of object function. Ph.D. Thesis. Atlanta: Emory University.

Defeyter, M. \& German, T. (2003). Acquiring an understanding of design: evidence from children's insight in problem solving. Cognition, 89, p. 133-155.

Dennett, D. C. (1978). Brainstorms: philosophical essays on mind and psychology. Cambridge, London: Bradford Books.

Dennett, D. C. (1989). The Intentional Stance. Cambridge, MA: MIT Press.

Dennett, D. C. (1990). The interpretation of people, texts and other artifacts. Philosophy and Phenomenological Research, Fall Supplement, 176-194.

Dennett, D. C. (1995). Darwin's dangerous idea: evolution and the meanings of life. New York: Simon \& Schuster.

Dipert, R. (1993). Artifacts, Art Works and Agency. Philadelphia: Temple University Press. 
Diesendruck, G., Markson, L. \& Bloom, P. (2003). Children's reliance on creator's intent in extending names for artifacts. Psychological Science, 14, 2, p. 164-168.

Dubpernell, G. (1978). Evidence of the use of primitive batteries in antiquity. G. Dubpernell, J.H. Westbrook (eds.), Selected topics in the history of electrochemistry, Princeton NJ: The Electrochemical Society, p. 1-22.

Eggert, G. (1996). The enigmatic 'Battery of Baghdad' — scientific theories on the ancient uses of a 2,000 year old finding. The Skeptical Inquirer, 20(3), p. 31-34.

Gelman, S.A. \& Bloom, P. (2000). Young children are sensitive to how an object was created when deciding what to name it. Cognition, 76, p. 91-103.

German, T. \& Johnson, S. (2002). Function and the origins of the design stance. Journal of Cognition and Development, 3, p. 279-300.

Gould, S. J. \& Lewontin, R. (1979). The spandrels of San Marco and the Panglossian Paradigm: a critique of the Adaptationist Programme. Proceedings of the Royal Society, B205, p. 581-598.

Graham, S.A., Williams, L. \& Huber, J. F. (1990). Preschoolers' and adults' reliance on object shape and object function for lexical extension. Journal for Experimental Child Psychology, 74, p. 128-151.

Hampton, J.A. (1995). Testing the prototype theory of concepts. Journal of Memory and Language, 34, p. 686-708.

Jansen, W., Fickenfrerichs, H., Peper, R., \& Flintjer, B. (1993). Die Batterie der Parther und das Vergolden der Bagdader Gotdschmiede. Chemie in Labor und Biotechnik 44(3), p. $128-133$.

Jaswal, V. K. (2006). Preschoolers favor the creator's label when reasoning about an artifact's function. Cognition, 99, p. 83-92. 
Gebelein, H. (1991). Alchemie. Munchen: Diederichs.

Kelemen, D. (1999a). Beliefs about purpose: on the origins of teleological thought. In M. Corballis, S.E. Lea (eds.), The descent of mind: psychological perspectives on human evolution. Oxford University Press.

Kelemen, D. (1999b). The scope of teleological thinking in preschool children. Cognition, 70, p. 241-272.

Kelemen, D. \& Carey, S. (2007). The essence of artifacts: developing the design stance. In E. Margolis and S. Laurence (eds.), Creations of the mind: essays on artifacts and their representation. Oxford University Press.

Kemler Nelson, D.G., Heron, L. \& Morris, C. (2002). How children and adults name broken objects: inferences and reasoning about design intentions in the categorization of artifacts. Journal of Cognition and Development, 3, 3, p. 301-332.

Kemler Nelson, D.G., Holt, M.B., \& Chan Egan, L. (2004). Two- and three-year-olds infer and reason about design intentions in order to categorize broken objects. Developmental Science, 7, 5, p. 543-549.

Konig, W. (1938). Ein galvanisches Element aus der Partherzeit?. Forschungen und Forschritte, 14(1), p. 8-9.

Landau, B., Smith, L. \& Jones, S. (1998). Object shape, object function and object name. Journal of Memory and Language, 38, p. 1-27.

Malt, B.C. \& Johnson, E.C. (1992). Do artifact concepts have cores? Journal of Memory and Language, 31, p. 195-217.

Matan, A. \& Carey, S. (2001). Developmental changes within the core of artifact functions. Cognition, 78, p. 1-26. 
McLaughlin, P. (2001). What functions explain: functional explanation and self-reproducing systems. Cambridge, MA: MIT Press.

Ortiz de Montellano, B. (1991). Multicultural pseudoscience: spreading illiteracy among minorities. Skeptical Inquirer, 16, 1, p. 46-50.

Paszthory, E. (1989). Electricity generation or magic? The analysis of an unusual group of finds from Mesopotamia. MASCA Research Papers in Science and Archaeology, 6, p. 31-38.

Preston, B. (1998). Cognition and tool use. Mind and Language, 13, 4, 513-547.

Siegel, D.R. \& Callanan, M.A. (2007). Artifacts as conventional objects, Journal of Cognition and Development, 8, 2, p. 183-203.

Salmon, M.H. (1982). Philosophy and Archaeology. London: Academic Press.

Sloman, S.A. \& Malt, B.C. (2003). Artifacts are not ascribed essences, nor are they treated as belonging to kinds. Language and Cognitive Processes, 18, 563-582.

van Amerongen, M. (2007). The interpretation of artifacts. Ph.D. thesis. Eindhoven, Delft: Simon Stevin Series in the Philosophy of Technology.

Vermaas, P. \& Houkes, W. (2003). Ascribing functions to technical artefacts: a challenge to etiological accounts of functions. British Journal for the Philosophy of Science, 54, p. 261-289.

von Daniken, E. (1993). Raumfahrt im Altertum. Munchen: Bertelsmann.

Wimsatt, W.K. Jr., \& Monroe, C. (1954). The Intentional Fallacy. The Verbal Icon: Studies in the Meaning of Poetry. Lexington: University of Kentucky Press. 


\section{${ }^{2}$ NOTES}

[1] Such explanations come about by taking, what Dennett calls, the intentional stance. The stance works as follows: "First you decide to treat the object whose behavior is to be predicted as a rational agent; then you figure out what beliefs the agent ought to have, given its place in the world and its purpose. Then you figure out what desires it ought to have, on the same considerations, and finally you predict that this rational agent will act to further its goals in the light of its beliefs (Dennett, 1989, p. 17)."

[] Indeed, when talking about design in nature, Dennett often refers to "Mother Nature" and her intentions. But this is more out of heuristic considerations; it makes biological interpretations easier and more comprehensible (see also section 6).

${ }^{3}[]$ The Antikythera mechanism is an object discovered in 1900 in a shipwreck, dating from ancient Greece, "an astonishingly complex assembly of bronze gears (Dennett, 1990, p.183)."

${ }^{4}[]$ We thank an anonymous referee for drawing our attention to this ambiguity.

${ }^{5}[]$ This was already apparent in a previous quote (see section 2), originally formulated by Wimsatt \& Beardsley, and used by Dennett as an epitaph to (Dennett, 1991): "It is only because an artifact works that we infer the intention of an artificer (italics added)."

${ }^{6}[]$ The meaning these scholars give to the design stance differs from Dennett's original in yet another way. Whereas Dennett sees the design stance at work in the interpretation of both artifacts and biological items, the cognitive psychological variant only applies to artifacts.

?[] Similar observations are made by authors not explicitly referring to the term "design stance", such as Bloom, 1996; Jaswal, 2005. 
${ }^{8}[]$ Similar results were obtained in a study by Matan and Carey (2001). In their experiment, adults, sixyear-olds, and four-year-olds were presented with a prototypical teapot which was used to water plants. When asked, most adults and six-year-olds judged the artifact still to be a teapot, whereas four-yearolds thought it to be a watering can.

9[] A way out here would be, according to Dennett, adopting a physical stance, i.e. a stance in which one appeals to the physics of the object in question.

${ }^{10}[]$ In fact, the design stance may be an innate strategy that evolves autonomously, meaning we may have reason to think that it has, indeed, a proper natural function. Or it may have developed out of a biological design stance-i.e. a stance for the interpretation of biological functions- that happens to be applied to artifacts. Alternatively, it may be a product of cultural evolution, implying it is a culturespecific stance.

${ }^{11}[]$ Gebelein (1991) for instance notes that in alchemy copper and iron symbolize two important gods, respectively Venus and Mars. 